\title{
Gamification for the Ancient Kingdom of Nusantara with User-Centered Design Approach
}

\author{
Yulyani Arifin', Martin², Ryan ${ }^{3}$, and Ryan Dratama ${ }^{4}$ \\ ${ }^{1,2,3,4}$ Computer Science Department, School of Computer Science, Bina Nusantara University \\ Jln. K.H. Syahdan No. 9, Jakarta Barat 11480, Indonesia \\ ${ }^{1}$ Yarifin@binus.edu; ${ }^{2}$ martinfitzlaw@gmail.com; \\ 3harukaze.ryota@gmail.com; ${ }^{4}$ rdratama@outlook.com
}

Received: $20^{\text {th }}$ November 2017/ Revised: $16^{\text {th }}$ December 2017/ Accepted: $18^{\text {th }}$ December 2017

\begin{abstract}
How to Cite: Arifin, Y., Martin, Ryan, \& Dratama, R. (2018). Gamification for the Ancient Kingdom of Nusantara with User-Centered Design Approach. ComTech: Computer, Mathematics and Engineering Applications, 9(1), 9-14. https://doi.org/10.21512/comtech.v9i1.4171
\end{abstract}

\begin{abstract}
The purpose of this research was to conserve the history of Nusantara kingdoms with the interesting way for the students. The researchers proposed a method by combining the history of ancient kingdoms in Nusantara with the game. It was done by using gamification with the user-centered design approach. The data collection used questionnaires and literature review. Moreover, the researchers identified the resources by applying the gamification element, developing the game based on user requirement, and evaluating the usability testing. The result shows that the implemented gamification in learning Nusantara can attract the students to learn about history. Based on the result of usability testing that has already been tested using the prototype, it proves that the user interest to learn the history of the ancient kingdom in Nusantara is increased. The results also imply that gamification indeed is one of a suitable method to be used as a medium for students to learn about history, especially the ancient kingdoms in Indonesia.
\end{abstract}

Keywords: gamification, user design approach, ancient kingdom, Nusantara kingdoms

\section{INTRODUCTION}

Indonesia, also known as Nusantara, has several great kingdoms. It includes Kutai, Sriwijaya, Tarumanegara, and Majapahit. Nusantara is derived from the word "nusa" and "antara". "Nusa" means island and "antara" means between. Therefore, Nusantara means islands that are located between the other islands. Based on the pre-survey that has been conducted by the researchers previously, it shows that $65 \%$ of the students are not interested in learning history. Most of the reason is the teaching method or the way of delivering the lesson that is not attractive. Because of that, the researchers decide to attract students to be more interested in learning history by using gamification.

Gamification is a method to use game elements and mechanics to develop an interactive system. It can motivate and engage the users (Seaborn \& Fels, 2015). Games can be used to make students understand several lessons in their daily lives (Law et al., 2015). Moreover, some games have been developed for an educational purpose related to cultural heritage. For example, there is the Ancient Agora of Athens by Kontogianni and Georgopoulos (2015) and Coenen, Mostmans, and Naessens (2013). According to Deterding et al. (2011), the game design will use non-game context that is already implemented to achieve the game purpose. It is not easy to implement non-game context into a game. It needs user design approach to produce a meaningful gamification (Nicholson, 2012).

Ritter, Baxter, and Churchill (2014) said that usercentered approach design could affect users from the psychological, cognitive, and social aspects of users. Moreover, by combining gamification method with user-design approach, it can produce more meaningful gamification. Then, it will add the user experience in playing the game (Nicholson, 2012).

Similarly, gamification has been applied in Chinese learning through the mnemonic method. It is a language learning strategy by memorizing (Amiryousefi \& Ketabi, 2011; Ying, Rawendy, \& Arifin, 2016). Using the gamification, it increases the interest of the children to learn Chinese language (Rawendy et al., 2017).

Moreover, Nakashima, Sato, and Maruyama (2017) also applied gamification. It is for young people, so they are interested in learning history especially about the ancient Hinduism and Buddhism kingdom. It is by using the fun in playing games and utilizing gamification technology on car applications.

There is a quote from Diane Ackerman who said that the activity that is the brain's favorite for learning is playing (Poetry Foundation, 2017). Now, the learners are changing. They need a new way to learn some thing, especially for the millennial generation. They are always surrounded by the digital environment since they are in nursery. Thus, they are growing up with the digital technology. To attract their attention to learn something like history, the researchers must consider the way that is related to it. 
The researchers propose incorporating gamification methods on learning history. It is by using the user's needs with user-design approach as the proposed application design. It is in accordance with the needs of young people as users of this application. The purpose of this research is to produce a new learning method for students to learn history through casual game like a puzzle game and incorporating adventure elements in it. It can give challenges to motivate the players to complete the game. With the gamification of several components in the learning material in the ancient kingdom in Nusantara, this game aims to become a new method in the education process. Thus, this game can increase the interest of students to learn Indonesia history.

\section{METHODS}

The method used in this research develops the method used by Huang and Soman (2013). The researchers also implement gamification in education and combine it with user-centered approach (Abras, Maloney-Krichmar, \& Preece, 2004; Norman \& Draper in Pea, 1987; Page, 2014). The proposed method is by developing a game that applies gamification in history lesson. It is conducted by using user interface design focusing on the user requirement. It can be seen in Figure 1.

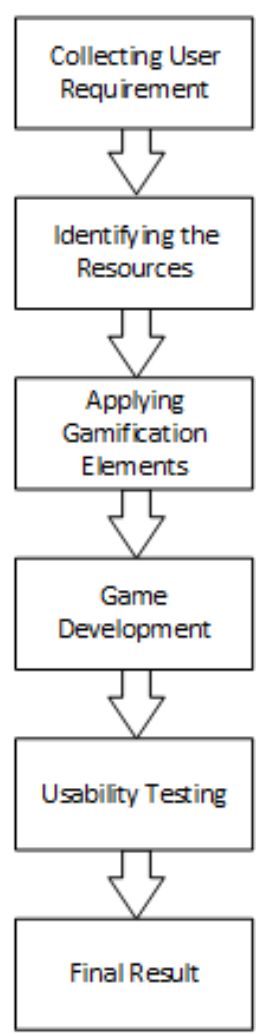

Figure 1 The Proposed Method

To produce game design in accordance with the needs of the user, the survey is divided into two parts. Those are pre-survey and survey. Pre-surveys are conducted to analyze the extent of teenagers and young adult's interest in history lessons. From the pre-survey results, many teenagers and young people are lack interest in history lessons especially related to the history of the kingdom in the past. Therefore, it is necessary to collect more data about the needs of a game application that attracts users in the history lesson. It is done through the distribution of questionnaires through online and offline. The questionnaires are sent to about 102 respondents. From the results of the questionnaires, the researchers analyze and formulate some user needs and what platform that is more desirable for user in using the game application. Questions asked in the questionnaires are divided into two parts. The first part is aimed at the information related to the ethnographic of the respondent. It includes the age of the respondents; what smartphone that is often used to know the platform used in the development of the application; how much time that is spent to use the smartphone, how the interest is in gameplay; time spent for playing games; and what kind of games that are often played. The second part of the questionnaire is more specifically related the topic of research that is about the history of ancient kingdoms. The question in this second part includes the level of interest in learning the history and knowledge of the ancient kingdom specifically about Hinduism and Buddhism and the extent of the interest of history through games.

The material on the history of the ancient kingdom is so many. Therefore, it needs to be adjusted to the several factors. It consists of subject matter used, the unit of measurement used that can be valued, time of work, and material level used. Identifying the resources of the material is necessary. The resources are related to an ancient kingdom. It should also be determined whether the level of resources is only the basis or includes further material. There is the need to specify resource measurement to measure the extent of success in understanding the material presented in the game. From the results of the resource, it has been determined to be applied in the design of the game. It can be a game asset or gameplay.

The next stage is to apply the process of gamification in educational games. The design of educational games consists of gamification elements used in the process. It consists of two major parts of self-elements and social elements (Huang \& Soman, 2013). Self-elements help users to recognize their potential. For example, there are points, levels, achievement badges, and simple time restrictions. Social elements help users to compete with others and share achievements in certain groups such as leaderboards, or high scores. This application is only used for single player, so the element of gamification used is self-elements. Element gamification used will be applied in designing game mechanics. It will affect gameplay and game balancing design.

To assist the process of game development, the result of the draft of resources and gamification element is created. It is in the form of documentation like game design document. After designing the game by applying gamification and user-design approach, it can proceed with developing game application as designed.

Then, it is followed by usability testing on respondents. It is to measure the extent to which the success of this application development is in accordance with the needs of users and can increase user interest in the history of ancient kingdom. Respondents are given the opportunity to try out the prototype of this game application and fill the evaluation questionnaires. From the results of usability testing, analysis and evaluation are conducted. It is to determine the extent whether this game application can affect user interest in learning the history of ancient kingdom. 


\section{RESULTS AND DISCUSSIONS}

Based on the results of questionnaires that have been distributed to 102 respondents, it consists of various ages. They are ranging from 12 years to 24 years. About $81 \%$ are users of Android-type smartphones, and $68 \%$ of the total respondents love to play games on smartphones. Gameplay that is often played about $58 \%$ is a puzzle game like Candy Crush and Bejeweled. Approximately $82 \%$ of respondents agree that learning history through games is an interesting method. It is a new way rather than textbooks. Moreover, $62 \%$ of the respondents love to learn history through puzzle games. Therefore, the proposed solution is to develop an educational game application. It should use a gamification approach based on user-design approach.

The game is designed to have a game play like Candy Crush. It is a puzzle-shaped game that has a type of match three puzzle or tile matching. It is a type of puzzle in which the player matches three or more tiles for the points. According to Rogers (2014), in designing match three puzzle, it consists of four foundations. There are manipulation, match criteria, obligatory matches, and times. These four foundations affect designing gameplay and affect game balancing.

The implemented historical material still uses the basic material. It is the introduction of the ancient kingdom through the relics of the time. Each kingdom has its relics such as relics of statues or tools at that time. Four kingdoms that become the resources are the kingdom of Kutai, Tarumanegara, Sriwijaya, and Majapahit. Each kingdom has some relics that are divided into several levels of the game. The level of the game starts from level 1 to level 7. A brief explanation is given at the beginning of the game for a particular kingdom. The game is started by giving a short story with picture as the prologue. The purpose is to set the point of view of user about the story that they will engage in the gameplay. Users are playing as an archaeologist and trap in dimension of an unknown time.

Moreover, the gamification element used is score and badges. The score is obtained based on match puzzle result done at every level of game. After completing a level of the game, the badges are given to the player who appears on the map in the game. The user needs to finish the mission by finding several given objectives. There are four great kingdoms that will be represented in the game. Those are Kutai, Tarumanegara, Sriwijaya, and Majapahit. The next gamification stages are on the design of the material used in the game. It can be seen in Table 1. As mentioned before, the gamification is the application of non-game elements into game elements. Then, the existing relics are used as targets or achievement goals in this game. The gamification will implement non-game context such as artifacts or relics that are related to each kingdom through the puzzle. The achievement of players is evident from how many relics can be collected. The game has gallery that will collect the relic or artifacts from user achievement.

From predetermined gamification element, the game balancing effect is designed from the level of difficulty. It has consistency that is level 1 to level 3. It has four different stone types. Moreover, the level 4 to level 7 has five different stone types. The next balancing game is to give every player a chance to try again if they are not successful on a mission. Therefore, there is no time limit for completing the in-game mission. If players often play, the time required to complete a mission becomes faster. This will affect the calculation of the value obtained. The game uses the first person point of view that starts with a story of the user helps the main character, a young archaeologist. The game engine that is used to develop the game is Unity3D (Oak \& Bae, 2014). The current game developed is only available on Android.

Table 1 Gamification Asset

\begin{tabular}{lll}
\hline \multicolumn{1}{c}{ The Relic } & Kingdom & $\begin{array}{c}\text { Non-Game } \\
\text { Context }\end{array}$ \\
\hline $\begin{array}{l}\text { Mulawarman } \\
\text { Inscription }\end{array}$ & $\begin{array}{l}\text { Kutai } \\
\text { Kingdoment }\end{array}$ \\
Avalokitesvara & Sriwijaya \\
Statue & Kingdom \\
& \\
Dewi Parwati & Majapahit \\
Statue & Kingdom & \\
& & \\
Ciaruteun & Tarumanegara
\end{tabular}

The researchers use pattern checking logic for the algorithm used in this game. The pattern check logic will create the puzzle pattern. Then, the game will recognize this pattern and deliver this pattern into the game. Thus, the game will be playable. There are six positional patterns used: three horizontal checks and three vertical checks. These patterns will be checked when the whole puzzle is created from above the screen. It makes sure that at least there are three numbers (can be modified) of the available match. The checking scenarios start from horizontal checks and vertical checks.

With this scenario, the game will recognize if the tile that will be summoned from above will fulfill one of the predetermined patterns. The pattern will check whether at least there are three tiles grid that can be matched. The players have to match the tiles, so the game will continue re-checking the pattern as the game running and keep summoning the tiles from above the screen. If the pattern check does not succeed. The game will scramble all the tiles in the whole grid, and do the pattern check again. Using this, it will give the player at least three scenarios to be matched. This pattern checking will be repeated until the end of the game. The puzzle is a tile-matching type of puzzle game. There are five different carves and colors to let the user differentiate the stones. It can be seen in Figure 2. Then, the structure of the proposed gameplay can be seen in Figure 3 .

The user starts the game by pressing the play icon in the middle. Then, there will be a brief story about the journey of a young archeologist in the museum, and suddenly unexpected journey is started. It is to find the ancient artifacts or relics. The player must accomplish all 
missions to return to where he/she comes from. The mission started from the first kingdom, Kutai. It can be seen in Figure 4.

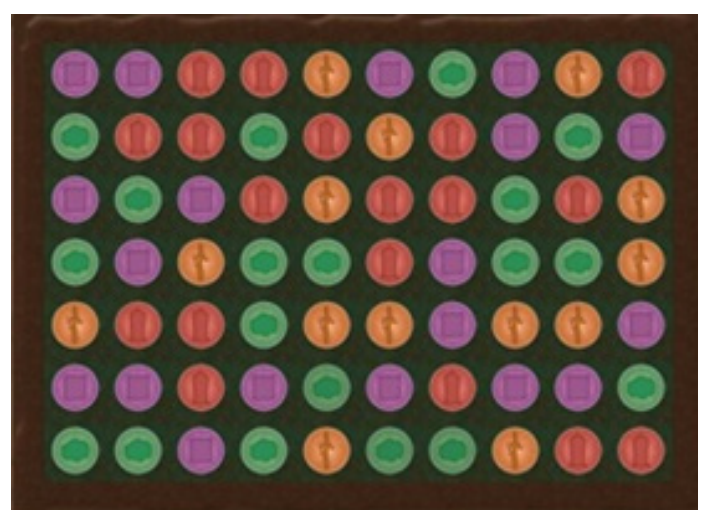

Figure 2 Component of the Puzzle

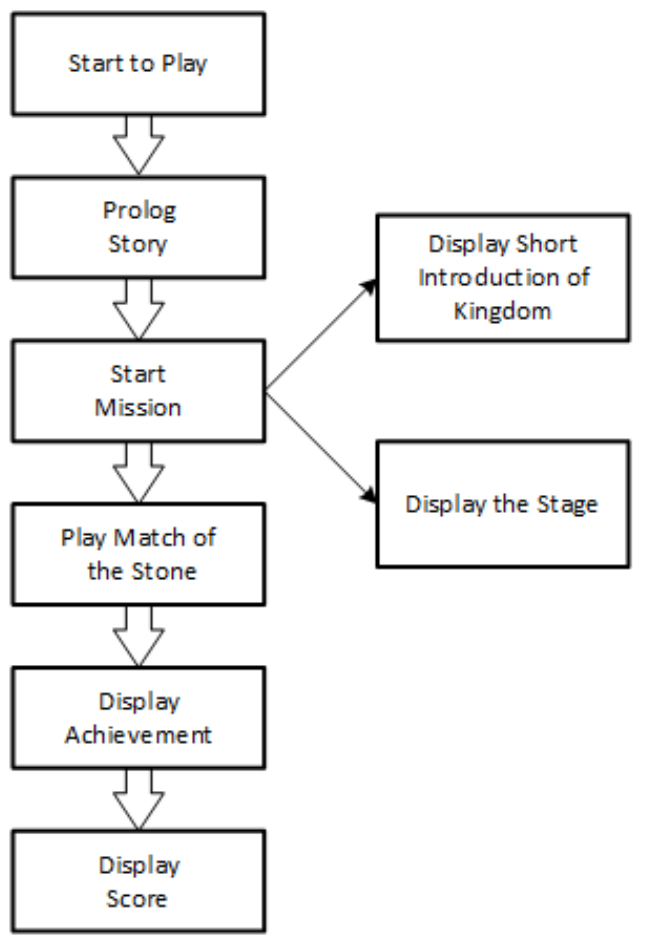

Figure 3 The Structure of Gameplay

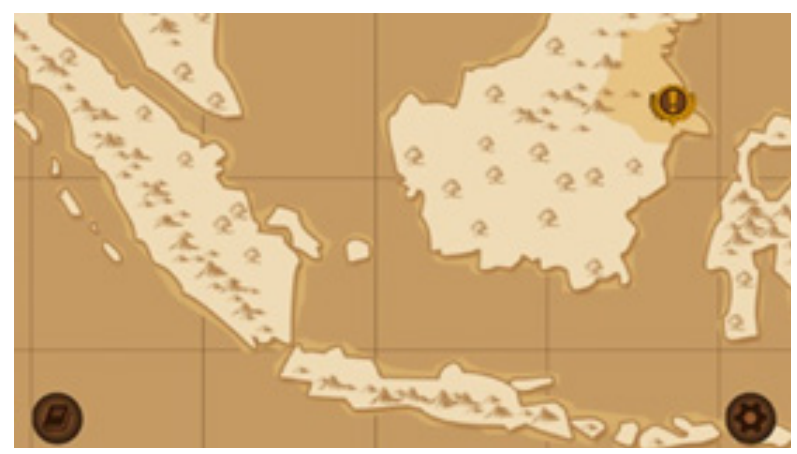

Figure 4 First Mission: Kutai Kingdom
Before the stage that user is going to play, there is a short introduction or explanation about the kingdom, the artifacts, or the relics. The purpose is to let the user learn about the history of the kingdom, the artifact, or the relic. For the puzzle, the interface is shown in Figure 5.

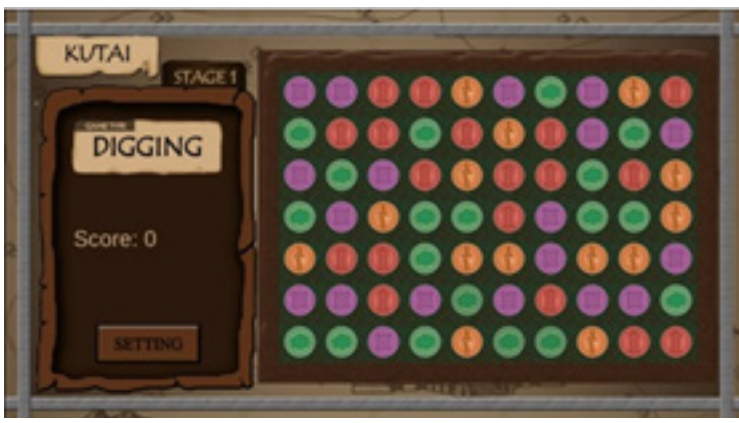

Figure 5 Stage 1 of the Game

The user needs to find the match of the stones. It can be minimum of three match stones with the same color and the same carve. The background is the ground that user will dig the destroyed tile in the puzzle. To complete the stage, user has to dig or destroy all the grass background. Then, the artifact or the relic buried will show up with a brief explanation. This can be seen in Figure 6.

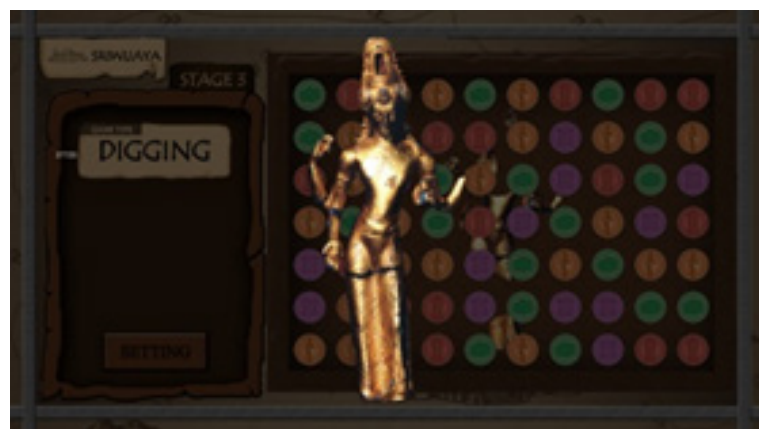

Figure 6 The Achievement

At the end of the mission, the scoreboard will be shown with the current score and the high score for that stage. After finishing a stage, the next stage will show up on the map. The mark of green check indicates the completed stage. Meanwhile, the yellow exclamation mark indicates the new stage that needs to be completed. The example is in Figure 7.

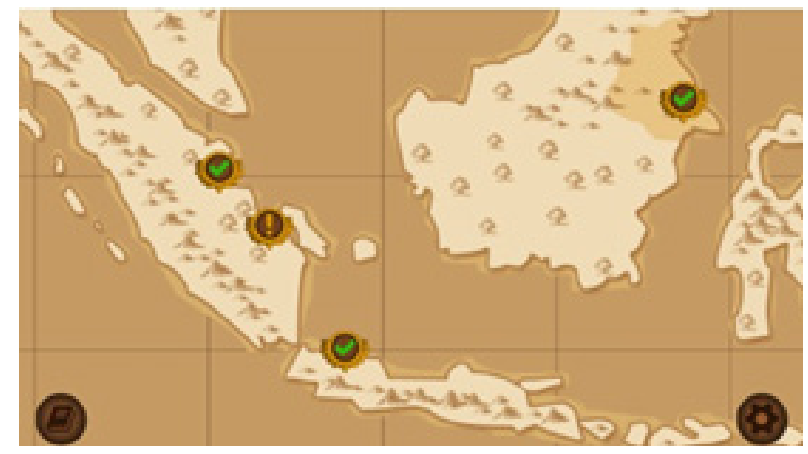

Figure 7 The Accomplish Stage 
Each stage has its difficulty. The higher the stage is, the more complex the game will be. The complexity is based on the type of stones in the puzzle. Therefore, the user can get more challenge when reaching the higher stage. The game will be finished after the user can complete all the missions.

The proposed games are tested on about 30 respondents through the usability testing method. Each respondent tries the prototype of this game and fills out the evaluation questionnaire. From the results of the evaluation questionnaire, it is found out that $94 \%$ of the respondents enjoy learning history through this game, and they agree that it is easy to understand the historical material shown in the form of gamification. About $82 \%$ of the respondents gain knowledge about the history of the ancient kingdom. Moreover, $81 \%$ of the respondents express an interest in learning the history in this games. Then, $88 \%$ of the respondents agree that the game is enjoyable to be played. Therefore, the summary of the questionnaire result shows that the respondents learn something about the ancient kingdoms through the game. They also agree that they are started to be interested in learning history of ancient kingdoms in Nusantara.

The gamification method applied in this proposed application is seen in the research of the history of the ancient Hinduism - Buddhism kingdom in the Nusantara. It starts from the Kingdom of Kutai. This is compared with memorizing the year of the founding of the kingdom to know which kingdom that is established first. It shows that it is more easily with gamification methods implemented in adventure game by completing the missions. The first mission starts from the kingdom of Kutai as the oldest kingdom in Nusantara. It is followed by the next mission according to the year of the subsequent kingdom. Then, the introduction of the relics of each kingdom is made as a target of the accomplishment of completing the mission. The relics provide information about the ancient kingdom which player will learn the information about the culture or life in that kingdom. This game provides an archaeologistlike experience who is searching for relics and information about the ancient kingdom. It can be discovered as the player experience the game, so the players will feel like they are looking for treasure themselves. This will make the game more interesting because the researchers use the curiosity of the players. The achievement results are unknown before the puzzle is solved successfully. When the player solves the puzzle, the full display of the relics will be shown to the player alongside with the information.

Another gamification that the user can identify easily is the carves from the puzzle pieces, which is called the tiles. The carves from the tile are designed from the relics of the old kingdom. It also is to give some hints to the player. The players will remember the relics because they will always see the carving in the tiles. Thus, it increases the educational side of this game. Some improvements can be made through this media.

The game uses user-design approach method. It can be seen in the design of simple gameplay. It has no deadline for completing a mission so that this game can be played by all levels of players from beginner players and expert players.

Using the data from the survey results, it shows that not all users are experienced in playing a puzzle game. Therefore, the researchers design the game to be simple with a straight learning curve. From game world that is designed using a multiplication situation that archeologists do, it can be seen from the design user interface. It adjusts to the context of the relic of the past. This makes users easily understand the information presented in this game application. In one of the principles of user-design approaches (Norman \& Draper in Pea, 1987), it is stated that the users can know the status which progress is being done. In this application, the raised badges are a sign of completion of a mission, so the users know how many missions that have been completed or unfinished mission. Then, the design gives the status of collected badges related to the application of self-element gamification.

\section{CONCLUSIONS}

Gamification with user design approach can offer the users more experience and improve their interest in learning something through game. Moreover, self-element gamification can help the users to encourage themselves to face the challenge in game. Using the gamification in learning the history of ancient kingdom can be one of the solutions to attract young people to learn history about their country.

For the future work, the game will be developed on another platform. It will also be improved with the virtual technology such as augmented reality. It is to improve the user engagement with the history of ancient kingdom in Nusantara.

\section{REFERENCES}

Abras, C., Maloney-Krichmar, D., \& Preece, J. (2004). User-centered design. In W. S. Bainbridge (Ed.), Encyclopedia of human-computer interaction. Thousand Oaks: Sage Publications.

Amiryousefi, M., \& Ketabi, S. (2011). Mnemonic instruction: A way to boost vocabulary learning and recall. Journal of Language Teaching and Research, 2(1), 178-182. http://doi.org/10.4304/jltr.2.1.178182

Coenen, T., Mostmans, L., \& Naessens, K. (2013). MuseUs: Case study of a pervasive cultural heritage serious game. Journal on Computing and Cultural Heritage (JOCCH), 6(2), 8.

Deterding, S., Dixon, D., Khaled, R., \& Nacke, L. (2011). From game design elements to gamefulness: Defining gamification. In Proceedings of the $15^{\text {th }}$ International Academic Mindtrek Conference: Envisioning Future Media Environments (pp. 9-15). ACM.

Huang, W. H. Y., \& Soman, D. (2013). Gamification of education. In Research Report Series: Behavioural Economics in Action. Rotman School of Management, University of Toronto.

Kontogianni, G., \& Georgopoulos, A. (2015). A realistic gamification attempt for the Ancient Agora of Athens. In Digital Heritage, 2015 (Vol. 1, pp. 377380). IEEE.

Law, E. L., Watkins, D. E., Barwick, J. P. L., \& Elee, K. (2015). Gamifying research on children's understanding of law in their lives. In CHI 2015 Workshop "Researching Gamification: Strategies, Opportunities, Challenges, Ethics." 
Nakashima, R., Sato, T., \& Maruyama, T. (2017). Gamification approach to smartphone-app-based mobility management. Transportation Research Procedia, 25, 2349-2360. http://doi.org/10.1016/j. trpro.2017.05.234

Nicholson, S. (2012). A user-centered theoretical framework for meaningful gamification. Games + Learning+ Society, 8(1), 223-230.

Pea, R. D. (1987). User centered system design: New perspectives on human-computer interaction. Journal Educational Computing Research, 3, 129134.

Poetry Foundation. (2017). Diane Ackerman. Retrieved from https://www.poetryfoundation.org/poets/ diane-ackerman

Oak, J. W., \& Bae, J. H. (2014). Development of smart multiplatform game app using UNITY3D engine for CPR education. International Journal of Multimedia and Ubiquitous Engineering, 9(7), 263-268. http:// doi.org/10.14257/ijmue.2014.9.7.22

Page, T. (2014). Skeuomorphism or flat design: Future directions in mobile device User Interface (UI) design education. International Journal of Mobile
Learning and Organisation, 8(2), 130. http://doi. org/10.1504/IJMLO.2014.062350

Rawendy, D., Ying, Y., Arifin, Y., \& Rosalin, K. (2017). Design and development game Chinese language learning with gamification and using mnemonic method. Procedia Computer Science, 116, 61-67. http://doi.org/10.1016/j.procs.2017.10.009

Ritter, F. E., Baxter, G. D., \& Churchill, E. F. (2014). Foundations for designing user-centered systems: What system designers need to know about people. Springer Science \& Business Media.

Rogers, S. (2014). Level up! The guide to great video game design $\left(2^{\text {nd }}\right.$ ed.). United Kingdom: John Wiley \& Sons.

Seaborn, K., \& Fels, D. I. (2015). Gamification in theory and action: A survey. International Journal of Human-Computer Studies, 74, 14-31.

Ying, Y., Rawendy, D., \& Arifin, Y. (2016). Game education for learning Chinese language with mnemonic method. In International Conference on Information Management and Technology (ICIMTech) (pp. 171175). IEEE. 